\title{
Claves filosóficas de Ignacio Ellacuria para reorientar la realidad histórica
}

David Jacob Romero García ${ }^{1}$

Recibido en Marzo 2012, aprobado en Julio 2012

\section{Resumen}

Es imperiosa la necesidad de discutir sobre el rumbo que tendrá nuestro país: El Salvador; pero el rumbo debe tener bases sólidas, no ideologías falaces. Ellacuría nos ilumina el rumbo: Sólo a través de la civilización de la pobreza se pueden desarrollar todos los pueblos de la Tierra.

\section{Palabras claves}

Estar en la realidad, actualización de posibilidades, civilización de la pobreza

\begin{abstract}
It is imperative the need to discuss the direction that our country, El Salvador, will take. Such direction must have a solid foundation, no spurious ideologies. Ellacuría lights the path: Only through the civilization of the poverty, all the peoples of the Earth can become developed.
\end{abstract}

\section{Keywords:}

being in the reality, possibilities updating, Civilization of the poverty

\section{Introducción}

El presente artículo pretende entrar a la dinámica profunda de la realidad histórica, no solo desde el ámbito formal en materia filosófica, aunque nos lleva la mayor parte, pero con el objeto de entender las causas fundantes de la realidad actual. Me serviré de las ideas del pensamiento de Ignacio Ellacuria, como uno de los teóricos-prácticos más elocuentes y objetivos que tuvo la

1. Catedrático Hora Clase de Humanística en la Universidad Don Bosco.

E-mail david.romero@udb.edu.sv 
humanidad para encontrar su idea propositiva: la civilización de la pobreza como movimiento dialectico de la civilización de la riqueza.

Como latinoamericanos debemos iniciar una alternativa real a los problemas más graves de nuestro continente. Ya no podemos permitir que los que dirigen la economía mundial lo hagan desde ideologías; es necesario crear propuestas científicas y reales en pro y desde las mayorías. El no hacerlo es un mal histórico que estaremos sumando a la siguiente generación, que son nuestros hijos e hijas.

\section{Definición real de la Historia²}

Para adentrarnos al conocimiento de la historia, como tratado filosófico, me voy a dejar guiar de la filosofía de Ignacio Ellacuría. Pero, antes es necesario conocer un poco la vida de Ignacio Ellacuría para conectar su vida y su pensamiento como entramado coherente entre vida e ideas: Fue en Portugalete, Vizcaya, donde nació Ignacio Ellacuría, un 9 de noviembre de 1930, en el seno de una familia de cuatro hermanos. Recibió la educación primaria en el mismo Portugalete, pero su bachillerato lo realizó en Tudela, Navarra, en el Colegio de los Jesuitas ${ }^{3}$.

Muy joven, a la edad de 16 años, ingresó en Loyola en el Noviciado de la Compañía de Jesús. Y dos años más tarde se ofreció como voluntario para ir a El Salvador, al noviciado de Santa Tecla, donde tuvo por maestro al P. Miguel Elizondo. El P. Elizondo era un hombre abierto, avanzado para su tiempo y de profunda espiritualidad, que supo aligerar las rigideces de la vida religiosa de aquel momento histórico, para confrontar a sus novicios con Jesucristo por medio de los Ejercicios. Quiso también adaptarlos a la peculiaridad de la cultura Centroamericana, permitiendo incluso que jugaran al fútbol sin sotana, algo impensable en su tiempo.

En 1949 marchó a Quito a estudiar humanidades y filosofía, junto a otros muchos compañeros jesuitas suyos de la Provincia Centroamericana. Si la biografía de un hombre pudiera recogerse a través de sus encuentros con seres humanos que le han influido y dejado una profunda huella, en esta etapa ecuatoriana de Ignacio deberíamos destacar la figura de dos personas: el P. Aurelio Espinoza Pólit y el P. Ángel Martínez. Del primero, autoridad mundial en humanidades, recibió la pasión por enseñar desentrañando la vida que se colaba por las tesis filosóficas clásicas, a veces tan frías, y con la creatividad que agita la literatura griega. El segundo, un poeta navarro destacado en la lírica nicaragüense, le impactó por la síntesis personal entre su pensamiento y su obra: “por eso estoy

2 Ellacuría, Ignacio. Filosofía de la Realidad Histórica. UCA Editores, San Salvador, 2007³. Págs. 491-596.

3 Esta reseña es deudora fundamentalmente del libro Jon Sobrino, R. Alvarado (Eds.), Ignacio Ellacuría, "aquella libertad esclarecida", Sal Terrae, Santander, 1999. 
deseando más y más cartas suyas, que me dicen muchas cosas que también son mías, pero que yo no sé decirlas si usted no me las despierta dentro"

En 1955 abandonó Quito con su título de licenciado en filosofía, para continuar con una nueva etapa de formación, esta vez el "magisterio", que realizó en el Seminario de El Salvador.

En 1958 continúa con sus estudios, esta vez teológicos, en Innsbruck, Austria. Nunca habló con gran entusiasmo de aquella etapa, exceptuando su valoración de Karl Rahner, profesor en aquel entonces de dogmática, asesor del Concilio Vaticano II y figura señera de la teología católica del s. XX. De él aprendió el valor teológico central de la cristología y la necesidad de unir la investigación teológica a la realidad humana. El sentido de la teología para Rahner no es servirse a sí misma, sino ofrecer relevancia vital, ser portadora auténtica de Buena Noticia, a cuyo servicio se encuentra, algo que Ignacio no olvidaría. En 1961 fue ordenado sacerdote en Bilbao.

Ese mismo año visitó a Xavier Zubiri por primera vez en Madrid, a quien pediría que dirigiera su tesis doctoral en filosofía, algo a lo que accedió excepcionalmente. Ignacio veía en él "un modelo de juntura entre lo clásico y lo moderno, entre lo esencial y lo existencial"5. Su tesis doctoral llevará por título La principialidad de la esencia en X. Zubiri. Durante aquellos años de 1962 a 1965 Ellacuría se convirtió en un interlocutor insustituible para Zubiri, más tarde continuador de su obra y, junto a Diego Gracia, su mejor alumno. Zubiri necesitaba de Ellacuría para publicar sus obras e impartir cursos. Su conversación y contraste le confirmaban y animaban: "Me resulta imprescindible e insustituible. Nadie como usted está tan compenetrado conmigo, y sólo en usted tengo depositada mi plena confianza"6. Desde 1967, en que ingresó en la sociedad de Estudios y Publicaciones que le pagaba el viaje, viviendo ya en El Salvador, pasaba todos los años entre dos y cuatro meses en Madrid junto a su maestro, estudiando y ayudándole a publicar. Fruto de aquellos años llegó la trilogía sobre la Inteligencia: Inteligencia y realidad, Inteligencia y logos, Inteligencia y razón. A la muerte de Zubiri, en 1983, Ignacio asume la dirección del Seminario X. Zubiri y queda como heredero intelectual de su obra.

Completó su formación jesuítica en Dublín, donde realizó su tercera probación y que le permitió pronunciar su profesión solemne el 2 de febrero de 1965 en Portugalete. En 1967 se incorpora a la Universidad Centroamericana José Simeón Cañas, UCA. En 1973 publica Teología política, que lo sitúa en el entorno de la teología de la liberación, y que lo confirma como intelectual comprometido con la realidad, como pensador que pretende unir reflexión e influencia social. En

4 Carta a Ángel Martínez, julio de 1954, en Escritos filosóficos I, San Salvador, 1996.

5 Carta del 3 de octubre de 1961.

6. Carta de 29 de enero de 1967. 
1976 asume la dirección de la revista ECA, Estudios Centroamericanos, desde la que hablará con valentía sobre la realidad del país. Uno de los momentos clave se produjo con la publicación de un artículo que llevaba por título "A sus órdenes, mi capital"7, dirigido al Presidente Molina, en el que criticaba al Gobierno por haberse echado atrás en su reforma agraria: "el Gobierno ha cedido, el Gobierno se ha sometido, el Gobierno ha obedecido. Después de tantos aspavientos de previsión, de fuerza, de decisión, ha acabado diciendo: A sus órdenes, mi capital". Aquel artículo costó a la UCA la supresión de la ayuda económica que recibía del gobierno.

En 1977, en la ofensiva contra religiosos que se desató en el país -todos los jesuitas son amenazados de muerte desde el 12 de marzo de 1977-, cayó asesinado el jesuita Rutilio Grande, un acontecimiento decisivo para el compromiso de Monseñor Arnulfo Romero, Arzobispo de San Salvador, que se convertiría en la voz más crítica y más escuchada del país y que sería abatido por las balas el 24 de marzo de 1980. La vida de Romero, su conversión a la causa de los pobres por obra de la fe, impactó enormemente en Ellacuría, nuevamente estremecido por una vida entregada a la denuncia profética y al desvelamiento de la verdad.

En 1980 comienza una larga guerra civil de 12 años, con un enfrentamiento continuo entre el FMLN -Frente Farabundo Martí de Liberación Nacional- y el Gobierno. Desde 1981 Ignacio plantea públicamente una salida negociada al conflicto salvadoreño, una pretensión que no abandonaría hasta su muerte. Pronto publicaría también Conversión de la Iglesia al Reino de Dios, en 1984, en la que propone un papel para la Iglesia.

En 1985 participa, junto al Arzobispo Rivera Damas, en el canje de la hija del Presidente Duarte por 22 presos políticos y 101 heridos de guerra. Este papel mediador le proporciona una capacidad inédita de diálogo e influjo con las partes en contienda. Ese mismo año abre en la UCA la Cátedra de la Realidad Nacional en la que invitaba a personalidades políticas, religiosas, sindicales a opinar sobre temas candentes. Este auditorio multiplica el alcance de su voz. Cuando él interviene, la sala se llena. Así pasa a adquirir una relevancia pública cada vez mayor, reclamado en Congresos extranjeros y frecuentemente presente ante las cámaras de televisión.

En aquel tiempo desarrolla su tesis sobre la tercera fuerza, criticada por la guerrilla revolucionaria al considerar que pretendía desinflar su vitalidad y abrir la puerta al reformismo capitalista. Él abogaba por una fuerza que rompiera con el esquema de explotación y opresión, acabando así con la injusticia estructural a la que respondía con violencia el movimiento revolucionario. 
A mediados de 1989 asciende al poder Cristiani. Con su llegada se abren esperanzas de un cambio en la postura del Gobierno en relación al diálogo. Ellacuría llega a afirmar en un artículo de la revista ECA que "se va consolidando en el gobierno la línea civilista de Cristiani, frente a la línea militarista de D’Aubuisson y la línea escuadronista de cabeza clandestina"8. Sin embargo, por primera vez comenzó a decir que ahora sí podía pasar, refiriéndose al asesinato, algo que no había considerado posible en 1980, cuando se desató la violencia que segó la vida de Romero y que se saldó con varias bombas explotadas en la Universidad y un ametrallamiento en la residencia de los jesuitas con más de 100 impactos. La relación de ARENA -partido de Cristiani- con EE. UU era diferente a la anterior etapa, y ahora se podían producir acontecimientos que anteriormente el gigante del Norte no habría permitido.

A primeros de noviembre Ellacuría recibió en Barcelona el premio de la Fundación Comín y regresó a la UCA el 13 de noviembre. La guerra había invadido la ciudad. Allí enseñó a sus compañeros el dinero recibido que llevaba en el bolsillo. Aquel lunes estaba presente en la comunidad la noche en que los soldados la catearon. No interpretó que aquel cateo supusiera un reconocimiento previo. Pensó que no debían ocultarse para no sugerir que hubieran hecho algo malo. Pero se equivocó.

El 16 de noviembre el propio Ejército Nacional entró en la Universidad, donde lo asesinó, junto a todas las personas que estaban en la comunidad aquella noche, sus compañeros jesuitas Ignacio Martín Baró, Segundo Montes, Armando López, Juan Ramón Moreno, y Joaquín López y López, así como Elba Julia Ramos, que trabajaba en la comunidad, y su hija Celina.

Su vida es expresión de un intelectual para la liberación, como expresión histórica de la Buena Noticia anunciada por el Evangelio, en el que la causa de los pobres, en contra de los oligarcas, militares y poderosos, tenía prioridad sobre el avance del conocimiento. Un compromiso que le costó la vida.

Después de esta no tan breve biografía puedo conectarme al tema que nos compete.

Para Ellacuría, cuando se habla de historia, se debe aproximar a través de 3 pasos:

8. "Revista de Estudios Centroamericanos”, (ECA), 1989. Págs. 633. 


\subsection{La historia como tradición tradente ${ }^{9}$}

\subsubsection{Transmisión tradente}

Hay que reconocer que el phylum humano ${ }^{10}$, por su carácter pluralizante, continuante y prospectivo nos ofrece el cuerpo material de la historia (el ser humano); pero el punto neurálgico de la perspectiva histórica dada por el humano es en términos de transmisión (formas somáticas y vivas, acumulación y enriquecimiento, y perfeccionamiento). $Y$ todo esto se debe a que el phylum humano es fundamentalmente transmisión. Y toda transmisión está diferenciada por el contexto y el momento real específico en que acontece. $Y$ todo lo anterior sucede porque "el hombre no sólo está entre cosas, como lo pueden estar otros animales, sino que está entre ellas realmente"11; donde las cosas para el humano no son cosa-estímulo, sino cosa-realidad. Por consiguiente, todo humano está en la vida, comprendiéndose como realidad en realización o realizándose entre las cosas reales. Por tanto, el hombre posee una realidad abierta a distintas formas de optar para seguir viviendo. Y por ello, las formas de estar en la realidad no se transmiten genéticamente; sólo se transmiten a través de lo psico-orgánico (es la disposición por y para al elegir tal o cuáles cosas). Por lo tanto

La historia no es simplemente transmisión de vida, no es simplemente herencia, sino transmisión de una vida que no puede ser vivida más que en formas distintas de estar en la realidad ${ }^{12}$.

El humano comienza su vida apoyado en algo distinto a lo genético, lo psicoorgánico y lo biológico, sino por su "estar" en la realidad que va determinando procesualmente mientras vive; al mismo es determinante la intromisión de otras vida humanas que de algún modo determinarán su modo de estar:

Cuando el hombre, animal de realidades, engendra otro animal de realidades, no sólo le transmite su vida, es decir, no solamente le transmite unos caracteres psico orgánicos, sino que además, inexorablemente y velis nolis - quiera o no - , le instala en un cierto modo de estar en la realidad ${ }^{13}$.

\footnotetext{
9. Lo tradente es proveniente del vocablo latino traditio (Tradición), pero tradición como entrega de los modos de estar en la realidad, no como compartimiento de naturaleza genética. Dicho de otro modo, tradición de quien entrega, no de quien recibe.

10. Refiérase al modo de evolución genética que el humano va adquiriendo en el proceso temporal de existencia como especie.

11. Ellacuría, Ignacio. Filosofía de la Realidad Histórica. Pág. 493.

12.Ellacuría, Ignacio. Dimensión Histórica del Ser Humano (DHSH): siete ensayos de antropología filosófica, Bogotá, 1982. Pág. 127. Citado en Filosofía de la Realidad Histórica, pág. 494.

13. Ellacuría, Ignacio. Filosofía de la Realidad Histórica. Pág. 495.
} 
El proceso histórico puede ser llamado concretamente tradición ${ }^{14}$.

Toda vida humana, por tanto, comienza sobre un modo de estar en la realidad por sus progenitores; pero no es exclusiva responsabilidad de ellos, sino depende de lo que hace quien recibe la información.

La tradición formal de sus formas de estar en la realidad es el mecanismo por antonomasia de lo histórico; es, más aún, un ingrediente formal de la historia, pero no es toda la historia. Lo genético es parte condicionante, pero no lo es todo. Ahora no se debe descartar que lo genético y la tradición son los dos componentes para integrar la historia, aunque lo tradente (lo entregado) es lo formal de la historia, pues la naturaleza nunca puede explicar la plenitud de lo histórico ${ }^{15}$.

\subsubsection{Los momentos estructurales de la tradición}

La tradición no implica recepción sin más. Ellacuria plantea que la especie humana más que receptiva es proyectiva (lo que recibe lo asume y lo proyecta en su vida). Por ello, la tradición posee un primer momento estructural llamado momento constituyente de asumir un modo de estar en lo real, que lo separa del tiempo y de lo genético o estructuras psico orgánicas biológicas. Al no tener claridad de su hacer en la realidad (tradición), el humano se siente abandonado: "En este sentido, tanto los individuos como los pueblos sin tradición son pueblos abandonados, es decir, pueblos privados de algo que lo están exigiendo intrínsecamente"16.

De un modo u otro, todos los pueblos reciben tradición (modos de estar). De esta forma la humanidad entera es sujeto constituyente de la tradición (diversos modos de estar que configuran otros modos de estar, que se prolongan en el tiempo, se complejizan y se dinamizan $)^{17}$.

La historia posee un segundo momento estructural, el momento continuante, no sólo por su carácter de continuación, sino que lo impulsa hacia adelante, lo cambia. Ante una realidad sentientemente aprehendida (capacidad humana de captar las cosas reales como completitud, y no desmembrada, como la tradición racional ha reducido), como lo es lo humano, nunca lo entregado será recibido plenamente, sino que asumirá un modo propio, y se pregunta: ¿Qué es lo que continúa de la tradición? Pues nunca una realidad será igual que otra, hay un forzoso cambio entre lo que se recibe o lo que se vive. Por todo esto, el momento continuante de la tradición no es meramente repetición.

14 Ibíd., pág. 495. Cfr. DHSH, pág. 127.

15. Ibíd., Pág. 497.

16. Ibíd., pág. 498.

17. Ibídem. 
El tercer momento estructurante de la tradición es el momento progrediente. El humano tiene que realizar su vida recibiendo y transformando la tradición en un modo propio. Y el carácter especifico de la tradición es la necesidad de "no poder estar quieto", debido al momento prospectivo de la especie, la forzosa estructura de nacimiento, generación y muerte; y porque la tradición tradente enlaza individuos y situaciones. Y esta tradición tradente es en sí misma dinámica por su intrínseca referencia a las realidades dinámicas; y desde, si mismo, obliga a optar. Por tanto, la tradición es principio de dinamismo histórico: y es forzosamente progrediente, porque es constituyente y continuante ${ }^{18}$.

\subsubsection{El sujeto de la tradición}

Pareciese que la tradición es de individuos a individuos, pero estamos entendiendo la tradición como raíz de la historia, y no como la historia misma. Por tanto, el sujeto de la historia y el sujeto de la tradición no es lo mismo. De ahí, el sujeto se desdobla en dos: el sujeto que se hace historia, y el sujeto que padece tradición o historia; pero ambos padecemos y sufrimos la tradición ${ }^{19}$. Ahora adentrémonos en el sujeto de la tradición. La posición de Zubiri es taxativa:

El sujeto inmediato de la tradición es la especie, el phylum, vector de la tradición, porque son afectados por pertenecer a el por influencia. Esta tradición, la Paradosis ${ }^{20}$, como influencia tiene dos aspectos muy distintos, pero esencialmente conexos. Estos dos aspectos son concretamente los dos modos según los cuales puede la tradición afectar a los hombres: su actividad filetica y su actividad individual. Por ello, la tradición no es transmisión entre individuos, pues posee un momento social. Lo social determina la individualidad por el contexto social o la determinación del contexto social por la determinación individual ${ }^{21}$. Esto no implica que la vida deje de ser personal. El hombre hace su vida con los otros y con lo otro, pero lo hace en alguna medida, y en ese hacer se autoposee ${ }^{22}$. Cuando se habla de alienación personal o social no elude la configuración de la propia vida.

\subsubsection{La impersonalidad de la historia y el Opus Operatum}

El hombre como social se convierte en sujeto activo y pasivo de la tradición. Los sujetos, como cuerpo social, transmiten tradición social. La historia es producto de la tradición social, aunque parezcan que hay seres humanos que singularmente producen cambios históricos (los descubrimientos, las nuevas tecnologías, etc.), son productos pasivos de la tradición social que los envuelve.

18. Ibíd., pág. 499.

19. Ibíd., pág. 500 .

20. Paradosis [Paradosis]: vocablo griego que significa Tradición; pero tradición como legado histórico.

21. Ibíd., pág. 502.

22. Ibídem. 
Por tanto, la historia posee un sujeto llamado cuerpo social. Lo que recordamos de las singularidades de un individuo es su biografía (y muchas veces se van a la tumba sus vidas personales), y sólo queda lo social (su aporte hacia los otros o que los otros retomaron de ellos): “Lo operado, una vez obrado, cobra su propia independencia y su propia efectividad, respecto de lo que ha sido como acción y como intención personal de su autor"23. La acción sigue siendo de la persona, pero ya no es personal, sino impersonal por el opus Operatum ${ }^{24}$. Lo operado por la persona conduce a la impersonalidad (lo que hago no posee alteridad real, solo se hace). Todo acto es de la persona, pero no totaliza a la persona ${ }^{25}$. Esto conduce a la lógica de la impersonalidad social (donde las acciones personales quedan incorporadas e integradas al cuerpo social:

Por ser cuerpo social, el sujeto último de la acción es en sí mismo impersonal, y por su agente histórico de lo que queda de su acción es también impersonal, por más que las acciones hayan sido acciones personales de unos individuos determinados ${ }^{26}$.

Por tanto, hay una historia social y otra biográfica. Esta reducción personal del Operatum no es formalmente idéntica a la reducción por la vía de la alteridad. La vía de la alteridad, su resultado es la sociedad. La vía del Operatum, su resultado es la vía de la historia, tanto social como biográfica, pero la acción como Opera Operata ${ }^{27}$, puede afectar el Opus Operatum:

La historia no surge sin más de la confluencia de las acciones de los individuos, sino de los individuos en cuanto constituyentes de un cuerpo social que como tal no se reduce a la suma de individuos (...). El obrar individual puede tener y tiene, cuando es realización formal de la persona, una cara estrictamente personal, pero tiene también una cara impersonal ${ }^{28}$.

\subsubsection{La historia dimensional y la historia modal}

El concepto modal de la historia es el modo de afectar impersonalmente a la persona y el de la biografía personal; son el concepto doble de la historia, y sus vehículos son las dimensiones en las que acontece dicha historia. Zubiri explica: "No todo suceso tiene carácter rigurosamente histórico; para ello es necesario que el suceso sea social en una u otra forma"29. La historia social no excluye a la persona, sino que reclama la historia biográfica, pero en lo que esta tiene de historia y no en lo que tiene de biografía personal.

23. Ibíd., pág. 502.

24. Del Latín: La obra es causada por él.

25. Ibíd., pág. 504.

26. Ibíd., pág. 505.

27. Del Latín: obra o acción ejecutada.

28. Ibíd., pág. 507.

29. Zubiri, Xavier. Sobre la Esencia, pág. 516. 


\subsection{La Historia como actualización de posibilidades}

Antes de adentrarnos en la comprensión zubiriana de la historia como actualización de posibilidades, es necesario aproximarse a la correcta comprensión de la historia, partiendo de las nociones incorrectas:

\subsubsection{Las Tesis insuficientes: vicisitud, testimonio y sentido}

El humano siempre se piensa en una realidad y se le advienen unas vicisitudes ${ }^{30}$ que acontecen como narración explicativa. La historia no es una vicisitud, sino un momento constitutivo de la realidad humana, una realidad que es formal y constitutivamente tradicionada y tradicionante. Esto equivaldría a reducir la historia en acontecimientos del azar. Por tanto, la tesis de la historia como vicisitud es insuficiente, porque priva a la historia de toda esencialidad respecto del hombre. Por tanto, el phylum y la tradición estarían en segundo plano. La historia siempre debe ser vista como testimonio, como realidad humana en continuidad ${ }^{31}$. El problema es que no se puede reducir la historia a lo transmitido como testimonio, obviando la naturaleza. Incluso en las cosas en que el testimonio existe, el testimonio no constituye tradición por ser expresión, sino por lo que en esa expresión acontece, a saber, porque, en y con la expresión entrega algo. Esta entrega, y no la forma atestiguada de la entrega, es aquello en que la tradición consiste. La tradición no es testimonio, sino entrega de realidad. Por tanto, el testimonio no aglutina la realidad histórica ${ }^{32}$. En cuanto a la tercera tesis (la historia como sentido), carece de lógica: cuando se habla de la historia como transmisión de sentido se subraya el significado, y no los actos que produce el humano. El sentido debe ser matizado mejor, pues el sentido posee dos aspectos: el sentir del sentido y el tener sentido. Es internarse a la realidad misma de tener sentido ${ }^{33}$. Es necesario que las acciones tengan un sentido, y por ello se busca el sentido de sus acciones humanas e históricas; pero hay una necesidad anterior: la necesidad de tener sentido. No es un sentido que se atribuye a alguien, sino lo que se encuentra por dar dirección. Por ello, el problema radica en que se transmite y el por que de la opción que se transmite y se asume (la opción transmitida y asumida de estar en la realidad). Por ende, se trata de transmisión y opción real ${ }^{34}$

\subsubsection{Las posibilidades históricas}

Podríamos decir que la historia consiste formalmente en la entrega de estar realmente en la realidad. $Y$ este modo puede ser producción o destrucción ${ }^{35}$.

30. Acontecimiento contrario al desarrollo o marcha de una cosa.

31 Ellacuría, Ignacio. Dimensión Histórica del Ser Humano. Pág. 142.

32. Ellacuría, Ignacio. “Dimensión Histórica del Ser Humano”. Pág. 143.

33 Ibíd., 143 y 144.

34 Ellacuría, Ignacio. Filosofía de la Realidad Histórica. Pág. 519.

35 Ibídem. 
La historia tiene un carácter procesual, como modo de sucesión, y al mismo tiempo de desaparición (dado la continuidad y constancia al asumirla). Lo que desaparece es precisamente la realidad de lo que ha pasado, y sin pasado no hay historia. Pero ¿Qué es lo que permanece? El pasado no desaparece completamente, entonces el presente seria creación de la nada. Hay que poner atención a lo que ocurre realmente en la tradición tradente - la entrega de un forma de estar en la realidad - basada en una doble necesidad: quien la entrega (lo filetico y lo social), y quien la recibe (buscando apoyarse en una forma concreta de estar en la realidad para empezar a buscar de si mismo su propia forma de estar en la realidad) ${ }^{36}$.

El humano puede y posee el poder de optar. Las posibilidades las recibe por entrega; mientras que el poder de optar, por transmisión genética, por aquella transmisión que hace surgir la verdadera libertad. Estas formas que se transmiten se llaman posibilidades. No se trata de algo imposible o posible, sino aquello que posibilita. Aquí el poder es optar. Las posibilidades no dan el poder para optar, pero si dan el poder optar. Pero, para ejercer ese poder se necesitan estrictamente posibilidades posibilitantes (aquellas que realmente son posibles y viables para la realidad que las busca). Si se tiene el poder para optar, no siempre se puede, porque no se cuenta con posibilidades reales. El humano puede crear posibilidades, pero esto no indica que que el que tiene el poder de opción asuma dicha dirección dada por el posibilitante. Pero las posibilidades necesitan, a su vez, del poder de opción para pasar a la acción, y con la acción pasar a su plena realización. Así, las posibilidades son las que dan paso a la vida humana y a la historia ${ }^{37}$. Las posibilidades dan el giro diferencial de la constitución natural, por ello la historia va transformándose y/o cambiando ${ }^{38}$ :

En cuanto realización de posibilidades, la acción no es un mero hecho: es suceso. El suceso es el hecho en tanto que realización de posibilidades, en tanto que por mi opción he determinado a las potencias a ejecutar su acto de acuerdo con las posibilidades para las que he optado. La realización de posibilidades es opción y, recíprocamente, opción es realización, cuando menos incoactiva, de posibilidades ${ }^{39}$.

Lo ejecutado ya no es un puro hecho, sino que es un suceso. Son las cosas, en modo de instancias o en modo de recurso, la que se nos hacen presentes como posibilidades ${ }^{40}$.

\footnotetext{
36 Ibíd. Pág. 520.

37 Ibíd. Pág. 521.

38 Ibíd. Pág. 522.

39 lbíd. Pág. 523.

40. Ibídem.
} 


\subsubsection{La apropiación de posibilidades:}

Al realizar tales o cuales posibilidades, las hago mías, me las apropio. Por tanto, toda opción tiene un momento físico de apropiación. Y esto es porque nadie está optando en el vacio sobre meras posibilidades abstractas, sino optando por un elenco concreto de posibilidades que le ofrecen un modo recibido de estar en la realidad. Por esto, historia es el suceso de los modos de estar en la realidad $^{41}$.

Ajustando este modo de explicación de apropiación de posibilidades, no incluye los modos impersonales; y propenderíamos a creer que la historia es únicamente personal. Pero, en la historia hay formas de apropiación impersonal al desembocar en formas de grupo o "sistema" de posibilidades que condicionan a los individuos.

Lo histórico consiste, entonces, en la transmisión tradente de las formas de estar en la realidad, en cuanto estas se convierten para el humano en posibilidades. Ahora bien, dada la indeterminación de las posibilidades, solo se puede hacer reales por apropiación. La apropiación es histórica, no por lo que tiene de opción personal, sino por lo que tiene de actualización de posibilidades; mientras que la opción es personal, no por lo que de histórico tengan las posibilidades, sino por lo que tienen de libres en su carácter mismo de posibilidades ${ }^{42}$. Por consiguiente, historia es transmisión de tradición tradente bajo dos notas esenciales de la historia: principio de posibilidades y actualización de posibilidades.

\subsubsection{El dinamismo de la posibilitación}

El pasado continúa como posibilitación que enlaza posibilidades históricas. Ante ello, Zubiri rechaza la postura de Augusto Comte que en cada etapa histórica sostiene mecanismos sociales propios: "El dinamismo de la historia no es el dinamismo social, sino el dinamismo de la posibilitación (...) Toda cosa concreta, por muy natural que pueda parecer, es materia histórica cuando se convierte en posibilidad actualizada como tal"43.

\subsection{La configuración actual de la realidad histórica}

\subsubsection{La realidad histórica del mal}

El mal formalmente está en la historia, y no en la realidad natural o biográfica de la persona humana. Este mal histórico adquiere formas concretas, que afectan al cuerpo social como un todo, y que tiene un poder que ya no es meramente posibilitante, sino algo que se apodera de mi vida en cuanto perteneciente a un 
de terminado momento histórico. Y visto este análisis desde la óptica teológica, se puede hablar de pecado histórico:

El pecado histórico, además de ser un pecado social y estructural, alude al carácter formalmente histórico de ese pecado: es un sistema de posibilidades a través del cual se vehicula el poder real de la historia ${ }^{44}$.

Más aun, en el caso del mal histórico, Ellacuria le llama mal común, que posee tres características: reconocido (evidente, demostrable), afecta profundamente a la mayor parte de las personas, y se debe a la capacidad de comunicarse y propagarse; y este mal posee un carácter estructural y dinámico (la capacidad de hacer malos a la mayor parte de los que constituyen la unidad social) ${ }^{45}$.

Tanto Ellacuria como Zubiri, entienden que el mal no es ninguna propiedad de la realidad, sino una condición de la realidad para el ser humano; por ello, sólo respecto del humano hay bien y mal, porque sólo respecto de alguien cobra sentido el bien o el mal. Son formas de respectividad de la realidad humana. Para Ellacuria, la superación del mal histórico sólo se puede lograr a través de un proceso de praxis histórica de liberación (acción ética que, a partir de posibilidades reales se busque superar dicho mal y, a la vez, la afirmación y la realización procesual de un bien común, entendido precisamente como una exigencia negadora del mal común dominante en una situación histórica determinada: comunicabilidad bienhechora, y con carácter estructural y dinámico $)^{46}$. Friedrich Hegel aporta al respecto: "Cada nuevo espíritu de un pueblo representa una nueva etapa en combate por el que el espíritu universal conquista su conciencia y libertad" 47 . Por ello, Ellacuria reacciona: "Lo que vale de cada individuo humano, vale también de la humanidad: con la elección de unas posibilidades no se compromete un futuro, sino que se imposibilitan futuros" 48 .

Una vez entendiendo la formalidad de lo que llamamos lo histórico, es importante enraizar esta reflexión en la lectura critica que Ellacuria denomina la civilización del capital.

\section{La civilización del capital}

Cuando hablamos de la realidad, especialmente de América Latina, no partimos de una situación neutra, sino de una situación profundamente deshumanizadora

44. Ibíd. Pág. 590. Cfr. Samour, Héctor. Voluntad de Liberación. El pensamiento filosófico de Ignacio Ellacuria. Pág. 339.

45. Cfr. Ellacuria, Ignacio. El Mal común y los Derechos Humanos. Apuntes de clase del curso de Derechos Humanos que Ellacuria impartió de Marzo a Junio de 1989.

46. Samour, Héctor. Voluntad de Liberación. El pensamiento filosófico de Ignacio Ellacuria. Pág. 342.

47. Ellacuria, Ignacio. Filosofía de la Realidad Histórica. Pág. 453.

48. Ibíd. Pág. 523 - 524. 
del hombre, donde una muy pequeña minoría de países que albergan una muy pequeña parte de la población mundial, explotan los recursos de la humanidad (aire, petróleo, materias primas, alimentos, cultura, poderío militar, capital, etc.), de una manera masiva; mientras que la mayor parte de los países donde viven la mayor parte de la población mundial, no pueden disfrutar de estos recursos ni siquiera de una forma mínima ${ }^{49}$.

Este nuevo orden mundial imposibilita la reproducción de la vida y perpetua una distribución injusta o depredatoria de los recursos mundiales en beneficio de unos $\operatorname{pocos}^{50}$. Esta situación de desarrollo y dependencia está en la raíz de los procesos imperialistas y coloniales de las grandes potencias, y estos fenómenos se radicalizan hasta el momento actual: una economía basada en la acumulación absoluta que niega la posibilidad desarrollo a la gran mayoría de la humanidad con el único propósito de mantener su poder (control, dependencia y sometimiento) $)^{51}$.

Según Ellacuria este descontrol deshumanizado de la civilización del capital provoca la ampliación de la brecha entre ricos y pobres; el endurecimiento de procesos de explotación y opresión, con fines más sofisticados; el desglosamiento ecológico progresivo de la totalidad del planeta; y la deshumanización palpable de quienes prefieren abandonar la dura tarea de ir haciendo su ser con el agitado y atosigante productivismo del tener, de la acumulación de la riqueza, del poder, del honor y de la más cambiante gama de bienes consumibles ${ }^{52}$.

Esto indica que hay un proceso de ruptura de la solidaridad del género humano que lleva a la absolutización del individuo. En América Latina es más importante ser ciudadano de un país poderoso y rico que ser humano; los ciudadanos poderosos poseen derechos y posibilidades efectivas de desarrollo integral. Esto demuestra, en sentido aristotélico, que lo accidental es más importante que lo substancial. A todas luces es un desorden ético fundamental, el cual se puede expresar de la siguiente forma: "lo que se hace para desarrollar a cada hombre va en menoscabo de todo lo humano y de todos los hombres" 53 .

Ante esta situación Ellacuria expresa que debe haber un proceso de liberación: proceso de mayorías populares para mayorías populares, que empieza por la liberación de las necesidades básicas, y construye después condiciones positivas

49. Samour, Héctor. Voluntad de Liberación. El pensamiento filosófico de Ignacio Ellacuria. Pág. 351. Cfr. Subdesarrollo y Derechos Humanos. Revista Latinoamericana de Filosofía, No. 25, 1992. Pág. 4.

50. Samour, Héctor. Opus Citatum. Pág. 351. Cfr. Ellacuria, Ignacio. Utopía y Profetismo en América Latina. Págs. 146-147.

51. Samour, Héctor. Opus Citatum. Pág. 353.

52. Cfr. Ellacuria, Ignacio El desafío de las mayorías pobres. Revista ECA ,1989. Pags.1076.

53. Samour, Héctor. Opus Citatum. Pág. 355. 
para el ejercicio cada vez mas adulto de la libertad, y para el disfrute razonable de las libertades sociales y políticas - económicas ${ }^{54}$.

\section{Alternativa: una sociedad de la pobreza}

Hay que aterrizar de una vez por todas que el desarrollo para los países pobres no vendrá por el aumento de los recursos, al igual que la escala de consumismo y depredación de recursos que hacen los países ricos, pues todo ello tiene un costo fatal para la humanidad y el planeta. Para Ellacuria el problema no es solo económico, político y ecológico, sino cultural, histórico e ideológico:

El estilo de vida propuesto en y por la mecánica de su desarrollo no humaniza, no plenifica ni hace feliz, como lo demuestra entre otros índices, el creciente consumo de drogas, constituido en uno de los principales problemas del mundo desarrollado. Este estilo de vida esta movido por el miedo y la inseguridad, por la vaciedad interior, por la necesidad de dominar para no ser dominado, por la urgencia de exhibir lo que no se tiene, ya que no se puede comunicar lo que es $\mathrm{s}^{55}$.

Estamos ante un grado máximo de insensibilidad humana, perdida de la autonomía e insolidaridad humana. Por ende, Ellacuría le llama al proyecto de humanización integral la civilización de la pobreza (mecanismo dialéctico a la sociedad de la riqueza), la cual debe poseer las siguientes características fundamentales:

La civilización de la pobreza [...] rechaza la acumulación del capital como motor de la historia y la posesión - disfrute de la riqueza como principio de deshumanización, y hace de la satisfacción de las necesidades básicas el principio del desarrollo y del acrecentamiento de la solidaridad compartida el fundamento de la humanización [...] La civilización de la pobreza se denomina así como contraposición a la civilización de la riqueza, y no porque pretenda la pauperización universal como ideal de vida [...]. Lo que aquí se quiere subrayar es la relación dialéctica riqueza-pobreza, y no la pobreza en sí misma. En un mundo histórico configurado pecaminosamente por el dinamismo capital-riqueza es menester suscitar un dinamismo diferente que lo supere salvíficamente $e^{56}$

La civilización de la pobreza se funda, según Ellacuria, en la civilización del trabajo, pero no el trabajo como dinamismo de acumulación de capital, sino por el dinamismo real del perfeccionamiento humano y la potenciación humanizante de su medio vital del cual forma parte, y al cual debe respetar.

54. Ellacuria, Ignacio. Utopía y Profetismo. Págs. 161.

55. Samour, Héctor. Opus Citatum. Pág. 359.

56. Samour, Héctor. Opus Citatum. Pág. 361. 
Apela la constitución de un orden económico que posibilite las necesidades básicas y que haga posible las facetas comunes del desarrollo personal y las posibilidades de personalización ${ }^{57}$. Un proceso donde el estado asuma formas más socializadas de desarrollo, donde promueva la iniciativa comunitaria y social - no delegada en gobierno, partidos caciques, etc. Se trata de superar la apatía social en la conducción de los procesos históricos sin tener que caer por eso en gremialismos o cooperativismos ${ }^{58}$.

Esto supone un nuevo orden político, más allá de la democracia liberal (el voto y la manipulación popular) y de los modelos colectivistas. Implica, además, un nuevo orden cultural, que debe empezar por desligarse de los modelos occidentales, que implica romper esquemas consumistas y estilos de vida imperialistas y superficiales que atentan contra toda la vida integral planetaria. La civilización de la pobreza, lejos de ser en lo cultural consumista y activista sin rumbo, tiende a ser naturalista y a potenciar las actitudes contemplativas y comunicativas. Una sociedad de la pobreza donde los Medios de Comunicación Social sean medios desalienadores, donde fomenten el compartir y la riqueza cultural propia, y no los modelos sofisticados y decadentes del mundo occidental. Se debe buscar una cultura para la mayoría, y no una cultura elitista. Esto, en el sentido de que toda cultura debe ser liberadora de ignorancias, de temores, de pretensiones internas y externas, en búsqueda de la apropiación de la verdad cada vez mas plena y de una realidad cada vez más plenificante ${ }^{59}$.

Según Ellacuria esto vendrá a través de la Revolución - la que pretende libertad desde y para la justicia, y la justicia desde y para la libertad, la libertad desde y para la liberación y no meramente desde la liberalización, sea esta económica o política, para superar así el mal común dominante y construir un bien común, procurado desde una opción preferencial por las mayorías populares ${ }^{60}$.

\section{CONCLUSION:}

Mas que elaborar conclusiones, quiero proponer motivaciones a todos aquellos que albergan todavía el carácter crítico ante la vida. También a aquellos que no se conforman con lo establecido, a los que son capaces de girar el timón de su vida en pro de una luz más clara que enfoque un horizonte de esperanza en la humanidad.

El atreverse a proponer alternativas liberadoras, como Ellacuria, indica no sólo utilidad intelectual, sino fundamentalmente sensibilidad humana; pero tampoco creer que la propuesta es la absoluta certeza unívoca de solución. No es más que una, que unidas a otras, nos acercamos a la correcta consecución

\footnotetext{
57. Ibíd. Págs. 361 y 362.

58. Ibíd. Págs. 363.

59. Ibíd. Págs. 364.

60. Ibíd. Págs. 365. Cfr. Ellacuria, Ignacio. Utopía y Profetismo. Págs. 178.
} 
apropiada de la verdad. Debemos aprender de la historia, y cada proceso debe servir para encontrar su esencia primigenia, su ilusión franca e inocente, y desinteresada.

Todo análisis serio, como ciencia crítica, busca contribuir a forjar lineamientos universales (cuando apela a la esencia axiológica de la realidad) y particulares (cuando responde apropiadamente a una región), que ordenen la conciencia humana en pro de su correcta realización, según su esencia natural.

El discutir sobre política, economía, ecología y filosofía antropológica, etc., no es para abstraer los problemas dentro de espacios de reflexión intelectual. Estos temas de discusión que propongo, surgen por la urgencia universal de soluciones que la realidad demanda imperativamente. Y desde el modo de sentir inteligente, nos grita diciendo: ¡ya no es posible permitir que se manipule la verdad desde ideologías insostenibles e irracionales!

El proceso globalizado de la economía está generando realidades con mayor acercamiento hacia la muerte. Pues contradictoriamente, en la actualidad hay sobreabundancia de riquezas (en pocas manos) y extrema pobreza (en porcentajes abrumantes a nivel mundial).

Es prioritario que todo ser humano que se sienta situado en el mundo, y prevalezca en él un modo inquietante de sus problemáticas, busque encontrar parámetros de solución a los mismos. Por ello, todo aporte en favor de la vida, y ésta en su modo complejo y diferenciado, es de por sí una contribución a plasmar y señalar con atenimiento las realidades que encubren injusticias, ideologías, mitos, etc.

La humanidad ha hecho un proceso real en su historia, pero quienes la han dirigido, poco o nada han contribuido a favor del desarrollo de sus ciudadanos concretos. $Y$ esto porque siempre han prevalecido evoluciones negativas del poder, donde grupos minoritarios han gozado de las riquezas y los bienes naturales, fundamentados en parámetros legales, la intimidación o presupuestos ideológicos. Por ello, es lógico el surgimiento de procesos de sublevación, subversión, revolución, como respuesta al fenómeno de injusticia sistematizada y generalizada. $Y$ en todo cambio se alberga la esperanza que el mismo desencadene modos nuevos de organizar la vida, su desarrollo y su realización.

Ahora, toda tesis que promulgue un cambio puede ser debatible; pero al constatar la existencia de las víctimas, ninguna idea puede superar este hecho; y provoca una especie de cólera sagrada a favor de las mayorías pobres. El repensar y criticar a favor de las víctimas, es optar, pero nunca absolutizar; 
debemos repensar proyectos reales que estén en íntima relación con las necesidades humanas y su correcto conocimiento real de las mismas.

Es momento de aportar en la historia. No podemos quedarnos observando cómo se destruye nuestro entorno. Hay que acercarnos al abismo no para determinar tirarnos hacia él, sino para pensar qué hacer para que nadie más se lance.

El apostar por el capitalismo neoliberal, es apostar por la negación de la vida de la presente generación y de las futuras. Hinkelammert usa la frase: "Hay de aquellos que viven en total desesperación". Con esto nos avisa de que cuando un ser humano ya está desesperado, le será muy difícil proponer cambios reales en si vida, en su sociedad y no habrá contribución histórica. Por ello, hagamos de nuestra existencia una esperanza solidaria e incluyente, que provoque en los otros una contagiosa transformación hacia la perfecta felicidad.

\section{BIBLIOGRAFIA}

Ellacuria, Ignacio El desafío de las mayorías pobres. Revista ECA ,1989. Pags. 1076.

Ellacuría, Ignacio. Dimensión Histórica del Ser Humano (DHSH): siete ensayos de antropología filosófica, Bogotá, 1982.

Ellacuria, Ignacio. El Mal común y los Derechos Humanos. Apuntes de clase del curso de Derechos Humanos que Ellacuria impartió de Marzo a Junio de 1989.

Ellacuría, Ignacio. Filosofía de la Realidad Histórica. UCA Editores, San Salvador, 2007³. Págs. 491-596.

Ellacuria, Ignacio. Subdesarrollo y Derechos Humanos. Revista Latinoamericana de Filosofía, No. 25, 1992. Pág. 4.

Jon Sobrino, R. Alvarado (Eds.), Ignacio Ellacuría, “aquella libertad esclarecida”, Sal Terrae, Santander, 1999.

Revista de Estudios Centroamericanos (ECA), 1976. Págs. 637-643.

Revista de Estudios Centroamericanos, (ECA), 1989. Págs. 633.

Samour, Héctor. Voluntad de Liberación. El pensamiento filosófico de Ignacio Ellacuria. UCA Editores, San Salvador, 2002. Págs. 338 - 364.

Zubiri, Xavier. Sobre la Esencia, Alianza Editorial, Madrid, 1984. Pág. 516. 